\title{
AC 2008-974: SUSTAINABLE RESEARCH AND DESIGN IN A CIVIL ENGINEERING SENIOR DESIGN COURSE
}

\section{Emily Callaway, CH2M HILL}

Emily Callaway is a Water Resources Engineer with $\mathrm{CH} 2 \mathrm{M}$ Hill with a strong interest in natural treatment, reuse, and watershed management. Emily is a member of the Water Environment Federations Young Professionals program.

\section{Sean St. Clair, Oregon Institute of Technology}

Sean St.Clair is an assistant professor in the Civil Engineering Department at Oregon Institute of Technology where he teaches structural engineering courses and conducts research in engineering education. Dr. St.Clair is also a registered professional engineer in Oregon and consults in the areas of timber and light gauge steel design and construction. 


\title{
Sustainable Research and Design in a Civil Engineering Senior Design Course
}

\begin{abstract}
In an effort to help students understand the broader impacts of land development, a significant sustainability component was added to a capstone senior design project course in a small civil engineering program. This year-long course traditionally involves students completing straightforward designs in the areas of structural, transportation, geotechnical, and municipal environmental engineering. In a recent administration of this course however, students were required to include significant and visible sustainability components in each of these four areas. The students were not given a definition of sustainability or any further explanation of expectations. While this initially caused frustration and aggravation, after a great deal of research and design the students came to understand and appreciate sustainable development. This paper will describe the process used to incorporate sustainability and the students' final designs.
\end{abstract}

\section{Sustainability}

Sustainable development, as defined by ASCE, is "the challenge of meeting human needs for natural resources, industrial products, energy, food, transportation, shelter, and effective waste management while conserving and protecting environmental quality and the natural resource base essential for future development."

For practicing civil engineers, sustainability should be more than just a buzz word; it should be an objective for each design, project, and development. The American Society of Civil Engineers (ASCE) Code of Ethics ${ }^{2}$ includes the following fundamental principle: "engineers uphold and advance the integrity, honor and dignity of the engineering profession by...using their knowledge and skill for the enhancement of human welfare and the environment." This principle is expounded upon in one of the fundamental canons ${ }^{2}$ : "engineers... shall strive to comply with the principles of sustainable development in the performance of their professional duties." Furthermore, the Code of Ethics includes Guidelines to Practice under the Fundamental Canons of Ethics ${ }^{2}$, four of which directly address sustainability.

- Engineers whose professional judgment is overruled under circumstances where...the principles of sustainable development [are] ignored, shall inform their clients or employers of the possible consequences.

- Engineers should seek opportunities to be of constructive service in civic affairs and work for...the protection of the environment through the practice of sustainable development.

- Engineers should be committed to improving the environment by adherence to the principles of sustainable development so as to enhance the quality of life of the general public. 
- Engineers should endeavor to extend the public knowledge of engineering and sustainable development.

\section{Sustainability in Engineering Education}

It is evident that the civil engineering profession considers sustainability and sustainable development to be very important and that each engineer should not only adhere to the principles of sustainability but should advance those principles throughout the profession and the general public. Unfortunately, few students possess an adequate level of understanding of what sustainability is and how it can be incorporated into professional practice. ${ }^{3}$ As a result of this disconnect, government agencies, industry partners, and professional societies are recommending, supporting, and in some cases requiring, the instruction of engineering students in sustainability. ${ }^{4}$

Different programs address the need for sustainability in the curriculum in different ways. Some programs have addressed this need by introducing it in a freshman design course ${ }^{5}$, implementing sustainability into already existing courses ${ }^{6}$, or developing new courses devoted entirely to the topic $^{7}$. These types of implementations, however, can be problematic because freshman may not possess the technical knowledge to fully appreciate and understand the topic, it is difficult to squeeze more information into already intense topics, and many programs are under pressure to reduce the number of courses and credits required for graduation. For these reasons, the civil engineering faculty at Oregon Institute of Technology decided to introduce the topic of sustainability at the senior-level in the capstone design course.

\section{Senior Design at Oregon Tech}

In order to address concerns related to insufficient team skills, lack of multidisciplinary experience, and poor communication abilities, a unique capstone design course was developed at Oregon Tech ${ }^{8}$. This year-long, three term course sequence was designed to allow students to participate in the complete design and development process of a civil engineering project, from initial conceptual plans to final engineering designs. The capstone project was first implemented in 2000 .

The first term of this senior project course focuses on the development of a conceptual plan and engineering proposal in response to a mock request for proposals (RFP). The civil engineering faculty chooses an undeveloped piece of land in the community and writes an RFP to loosely frame the project for the students. The faculty also creates a mock client by whom the RFP is issued. The client interacts with the students throughout the course in a simulation of the client/consultant relationship. The role of the client is carried out by a member of the community or faculty.

After the RFP is issued, the students are divided into four or five different conceptual groups to develop competitive site plans for the property. These site plans are presented to the faculty and community partners via written and oral engineering proposals describing how the engineering work required for the site plan will be accomplished. 
In the second term of the course, the faculty members choose the best site plan and proposal and award the project to the winning group. All of the students in the course then regroup into a single engineering firm consisting of different discipline-specific teams including environmental, transportation, structural, and geotechnical teams each led by an expert faculty member and perform the necessary engineering design related to the winning site plan. Technical communications faculty members are also involved to assist students with their communication skills and group dynamics. While working on the technical aspects of the design project, students also complete communication assignments such as progress reports, project logs, self assessments, and design summaries.

In the third the term of the course, students finalize their designs and prepare construction documents, including geotechnical reports, traffic impact analyses, municipal utilities plan and profiles, and structural drawings and details. Students also present their final designs to departmental faculty, other civil engineering students, and city and county officials through written and oral final reports.

Assessments of the course have found that while students are initially uncomfortable with the open-ended format of the course, they ultimately appreciate the real-world aspect of the course that is missing from many other, more structured courses. The open-ended format has allowed for the introduction of new topics or issues without significantly changing the structure, requirements, or outcomes of the course. For this reason, and others listed previously, the capstone design course was chosen as the most ideal location within the curriculum to introduce sustainability.

\section{Sustainability in the Senior Design Course}

Sustainability was included for the first time in the 2006-2007 school year. The client was a philanthropic entity with a mission to promote ecotourism and sustainability. An environmentally sensitive property was selected as the development site of a welcome center. The wording of the RFP was intentionally vague; the client did not ask for specific elements of sustainability but did stipulate that sustainability and ecotourism should be highly visible to the public in order to serve as an educational demonstration center. A $\$ 5$ million price cap was set, though the client did make it clear that the budget could be increased if warranted by an exemplary sustainable design.

It was left up the students to define sustainability and to determine how to apply it to a welcome center. The students quickly realized that sustainability encompasses the full spectrum of land development, from materials selection and sourcing, site design and environmental impact, waste reduction and disposal, and community economics.

It also became apparent that though the concepts of sustainability are universal, the applicability and implementation of various elements of sustainable development are specific to the region and to each project site. As such, students could not rely on general concepts for design, and looked instead to local resources for information on region-specific sustainable development. 
This introduced the idea that networking with and reaching out to unknown resources is an integral part of professional development.

The project site itself, as shown in Figures 1 and 2, posed unique challenges and opportunities for sustainability. The site was a 53-acre parcel adjacent to a water-quality impaired river. The land had historically been riparian habitat in an unconfined river system, but was significantly impacted by reclamation efforts of the 1940s. In recent years the parcel had been used as irrigated pasture land, but was purchased by the state department of transportation for development as a wetland mitigation bank. Current wetland delineations had to be considered, as did mitigation requirements for wetlands impacted by proposed construction. Additionally, the site was located far from any existing utilities, a significant barrier to tying-in to existing systems and a unique opportunity to explore off-grid alternatives.

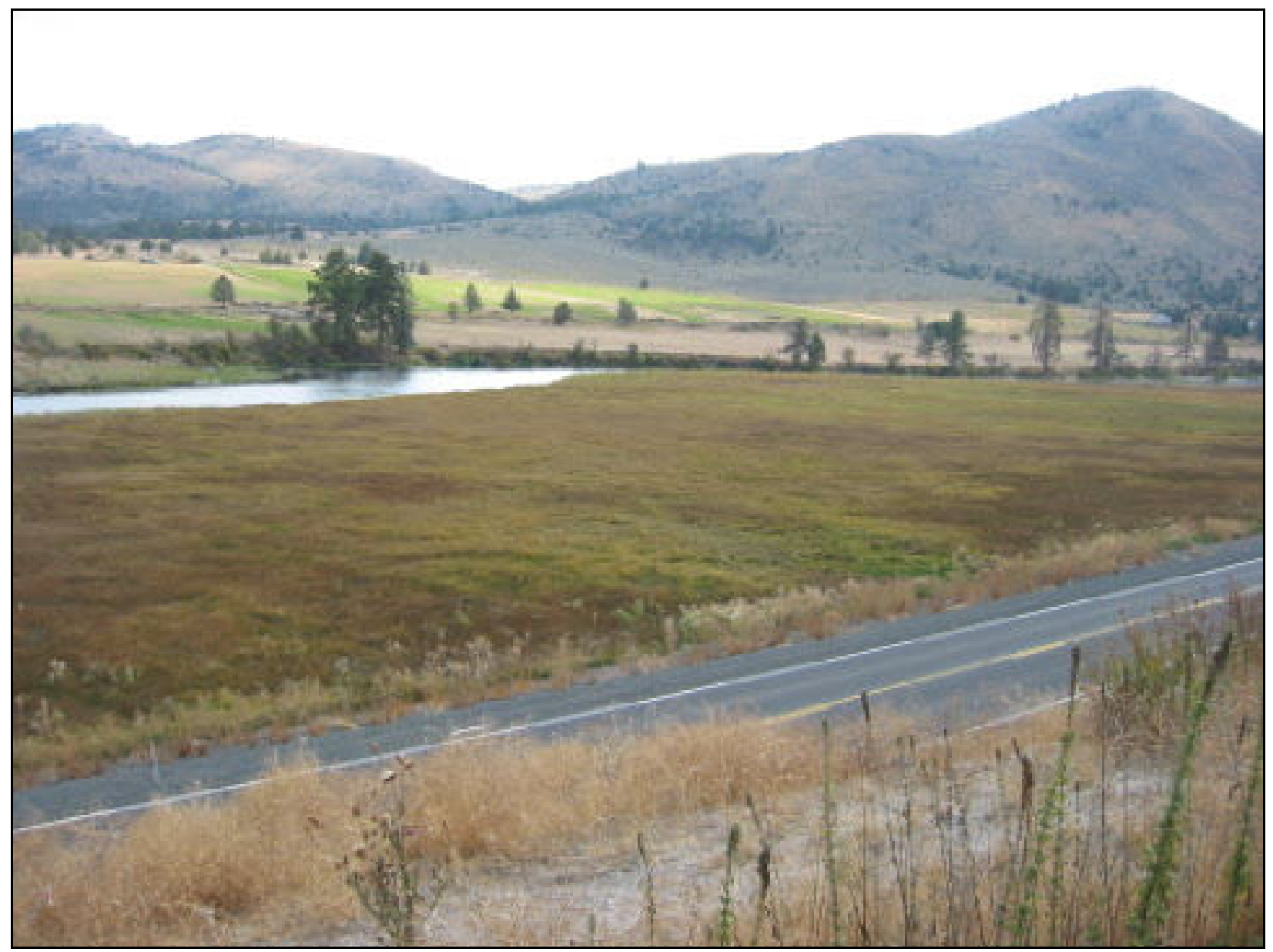

Figure 1: Looking south across project site

Each proposal team was also responsible for a construction cost estimate. Cost information for sustainable materials is limited and often proprietary, which forced the students to look to experienced professionals and vendors for information and to develop their own engineering judgment about first-costs and lifecycle costs. 


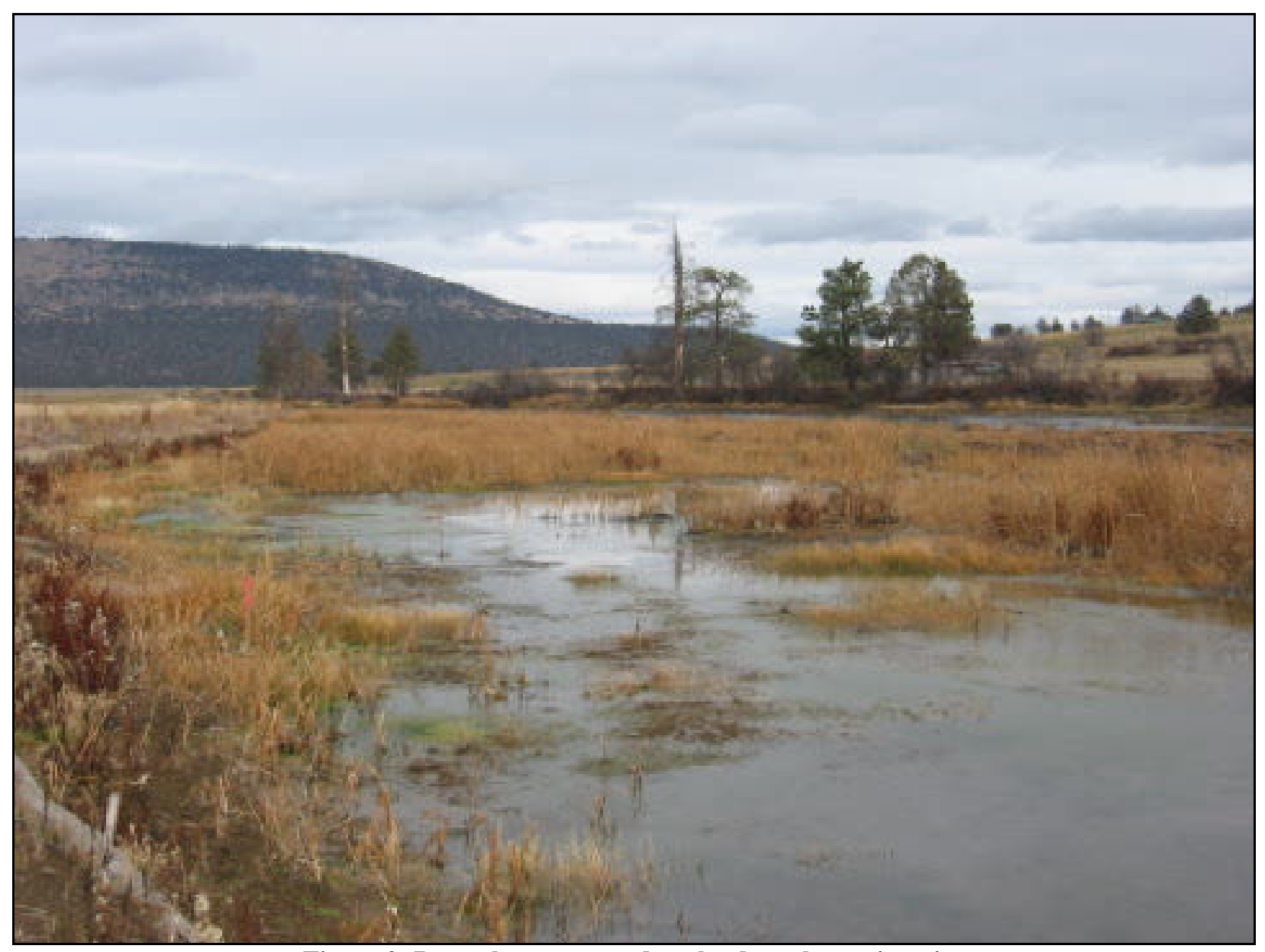

Figure 2: Recently constructed wetlands at the project site

Each proposal was presented to the senior design faculty and members of the engineering and regulatory community at the end of the first term. Rather than accept a single proposal in its entirety, the faculty combined elements from each proposal into a project that could reasonably be completed in the remaining two terms. Specific elements of the final site plan included a welcome center building, a parking lot and boat ramp, a trail system, and a constructed wetland. These components, along with some of the sustainable elements, are shown on the partial site plan in Figure 3.

The separate, competitive proposal teams were combined into one engineering firm. The engineering firm was subsequently divided into four discipline-specific teams, as in prior years. The geotechnical team was given the additional task of developing an energy efficient design to serve heating, cooling, and other electrical needs of the welcome center building. Each team was charged with carrying out their design to fulfill the highest level of sustainability. To assist the teams in meeting that goal, the students formed a committee to investigate requirements for LEED (Leadership in Energy and Environmental Design) certification. A member of each discipline-specific team was included on the LEED committee.

The second term involved in-depth research of the sustainable elements of the site. The students were split into two-person technology-transfer teams charged with investigating and reporting on 
a sustainable practice or material specific to their discipline. The research culminated in a written report and oral presentation to the firm. Students were also expected to proceed with conceptual design concurrent with their research.

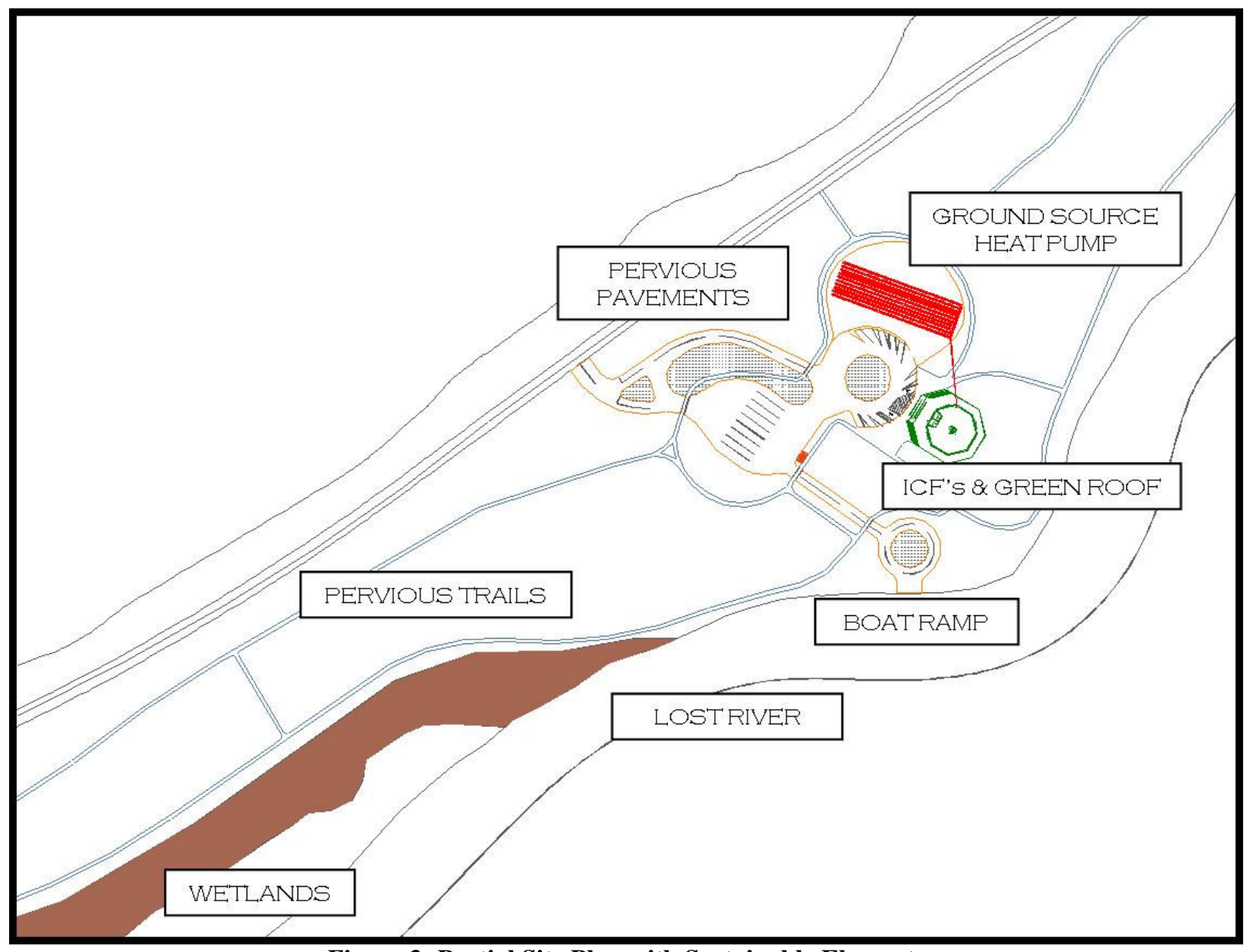

Figure 3: Partial Site Plan with Sustainable Elements

The technology-transfer presentations resulted in a greater firm-wide understanding of the various components of sustainable development which in turn fostered multidisciplinary collaboration as the design progressed.

Some examples of situations for which multidisciplinary collaboration was critical include the placement of both solar panels and a vegetated green roof atop the building, the use of composting toilets which required significant elevation within the building, and the construction of a closed-loop heating system beneath a pervious-pavement parking lot.

Each team had to maintain flexibility as other teams refined their design and learned more about their chosen technologies. Teams took advantage of email, cell phones, and brief conversations in passing to keep abreast of each other's developments.

The third term of the course was focused on finalizing design decisions and production of design drawings in addition to a final presentation of the project to the client, faculty, and community. 
Members of the environmental and transportation team collaborated on a model of the green roof and pervious pavements designed for the site.

\section{Objectives and Assessment}

The research objectives associated with the implementation of a sustainability component into the senior design course were as follows:

1. Improve students' awareness of sustainable development

2. Improve students' technical knowledge of sustainable development

3. Improve students' attitudes toward sustainable development

These objectives were assessed through student surveys; students were asked to rate their awareness of, technical knowledge of, and attitude toward sustainability prior to taking senior project and upon completion of senior project. Eleven out of 16 students participated in the survey and the results were analyzed using the Wilcoxon Signed Rank Test: a nonparametric analysis which was chosen because of the small number of participants and the ordinal level of data. The results from the ratings of student awareness are presented in Figure 4, which reveals that students' awareness of sustainability significantly increased $(Z=3.020, p<0.05)$ as a result of their senior project experience. The data summarized in Figure 5 reveal that the students' technical knowledge of sustainability also increased significantly $(\mathrm{Z}=2.965, \mathrm{p}<0.05)$. The ratings in Figure 6 show that a majority of the students initially had a neutral attitude toward sustainability prior to their senior project but had a very positive attitude towards sustainability upon completion of their experience, an increase that was statistically significant $(Z=2.859$, $\mathrm{p}<0.05)$. The assessment results suggest that introducing sustainability into the senior design course had the desired effect.

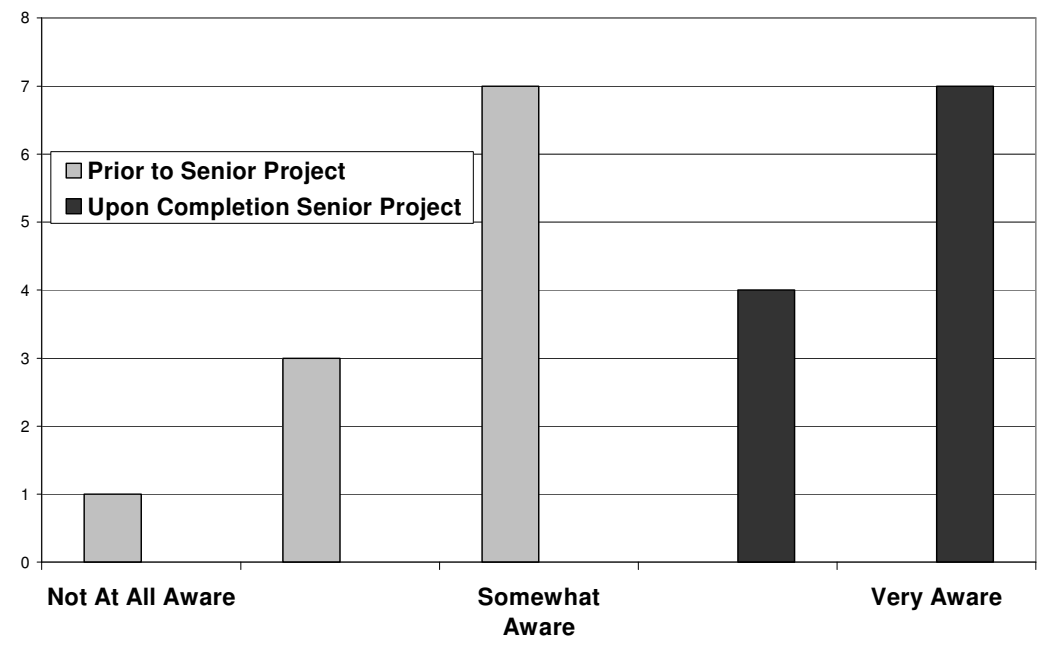

Figure 4: Students' Awareness of Sustainability 


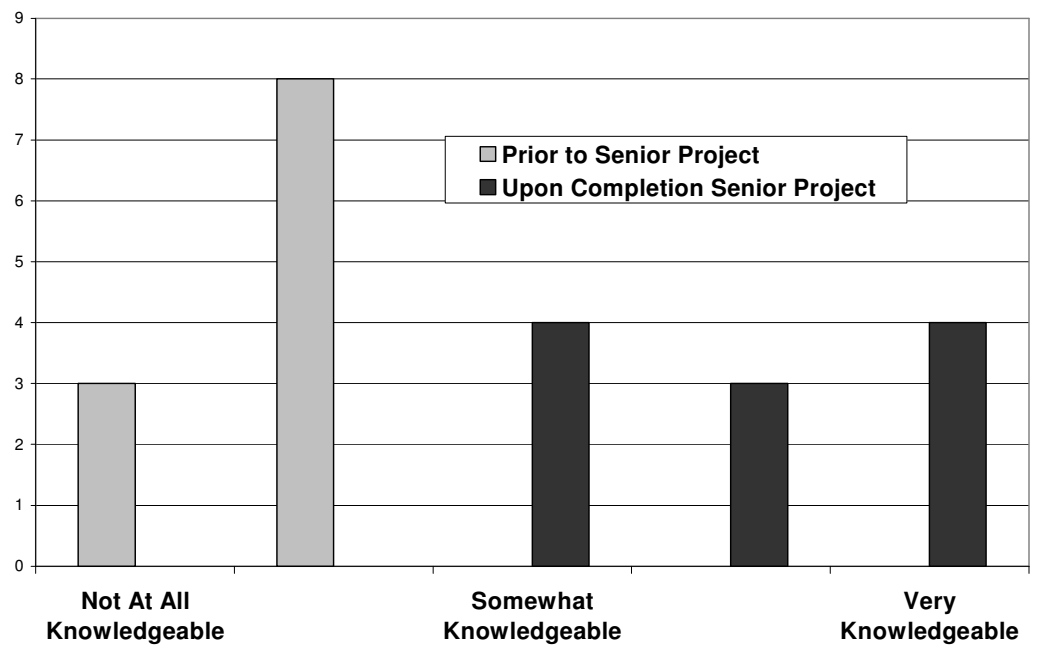

Figure 5: Students' Technical Knowledge of Sustainability

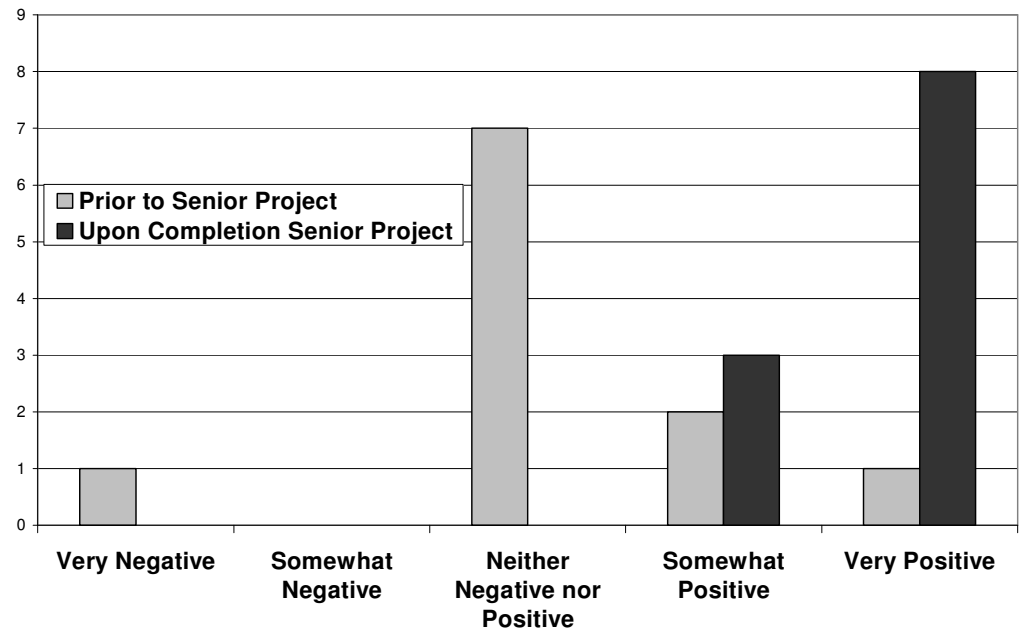

Figure 6: Students' Attitudes Toward Sustainability

The survey also asked the students to provide their own definitions of sustainability. Each of the definitions given was consistent with ASCE's definition indicating that students did increase their knowledge of sustainable development, especially considering that nearly seven months had elapsed between the conclusion of the course and the administration of the survey. Some examples of the students' definitions follow:

Sustainability is to use methods and ideals that minimize the impact of development in order to conserve resources for the future.

Sustainability is the ability to conserve our natural resources, while still making forward progress. The engineers of today and tomorrow have been handed the task of not only defining sustainability but also implementing it so that they may protect the health, wellness and safety of future generations. 
Sustainable design relating to civil engineering is the personal and professional responsibility or obligation to recognize the significance of designing all aspects of a project from initial transportation of materials and equipment to the site, through function of the project using as few natural or valuable resources as possible in order to provide future inhabitants of our area with the resources needed, and ultimately impacting the site as little as possible.

Students were also asked to provide any other comments they may have had on the topic of sustainability and its incorporation into senior project. A few of their comments are included below. These representative comments further suggest that implementing sustainability into senior project was beneficial for the students and their understanding of the topic.

I feel that the sustainability portion of senior project is great. One thing is that it forces students to become better critical thinkers than just problem solvers.

The company that I currently work for is moving towards the ideas of sustainability. I know that I am ahead of the curve due to my knowledge that I have gained from senior project. I am planning on becoming LEED accredited in the near future.

Sustainability is an important topic in today's developing world that is hard to define. Businesses want it, but do not necessarily know the requirements to make a building sustainable. Senior project was a great introduction into the vast realm of sustainability. Thanks.

Initially the concept of sustainability seemed overly emphasized. However, once I began researching and was introduced to the different ideas and types of sustainable design aspects, I began to understand more clearly the importance it had. It definitely became clear why this is such a growing concern in the field of civil engineering. Personally, it was a design concept that I had not worked with in any of my prior courses and through senior project I became familiar with the idea.

\section{Conclusions and Recommendations}

The incorporation of the topic of sustainability into a well established senior project course at Oregon Tech was met with positive results. The final designs presented by the students incorporated numerous sustainable components, revealing that they possessed a significant level of technical knowledge. And though both the students and faculty were initially frustrated with the introduction of the new topic and the additional research and design requirements, students' comments after the fact reveal a dramatic shift towards greater awareness of and more positive attitudes towards sustainability. Sustainability was included as a major component of the 20072008 capstone course, and the civil engineering faculty plan on requiring significant sustainability components in future course implementations. If favorable results persist for several years, sustainability may become a permanent part of the course. Other programs struggling with incorporating sustainability into existing curricula may find that addressing the 
topic in a capstone course would yield equally positive results. The open-ended student-led exploration of sustainability may have been the key factor in student interest in and retention of the ideas and fundamental design elements of sustainability.

\section{Bibliography}

1. American Society of Civil Engineers, (2007). Bylaws of the American Society of Civil Engineers., ASCE.

2. American Society of Civil Engineers, (2006). Code of Ethics., ASCE.

3. Mallick, R.B., Mathisen, R.P, and FitzPatrick, M.S., (2002). "Opening the window of sustainable development to future civil engineers." Journal of Professional Issues In Engineering Education and Practice., 128(4), 212-216.

4. Carew, A.L. and Mitchell, C.A., (2001). "What do engineering undergraduates need to know, think or feel to understand sustainability?" Sixth World Congress on Chemical Engineering. Melbourne, Australia.

5. Siller, T.J., (2001). "Sustainability and critical thinking in civil engineering curriculum." Journal of Professional Issues in Engineering Education and Practice., 127(3), 104-108.

6. Robinson, M. and Sutterer, K., (2003). "Integrating sustainability into civil engineering curricula." Proceedings of the 2003 American Society for Engineering Education Annual Conference and Exposition., session 2615.

7. Ciocci, R. (2006). "Teaching sustainable engineering ten years later: what's worked \& what's next." Proceedings of the 2006 American Society for Engineering Education Annual Conference and Exposition., session 1428 .

8. Cornachione, H.S., Cornachione, M.A., and Vance, V.J., (2004). "A capstone design approach in civil engineering." Proceedings of the 2004 American Society for Engineering Education Annual Conference and Exposition., session 2062. 